\title{
THE ANATOMY OF THE ANTERIOR ORIGIN OF THE DELTOID
}

\author{
V. P. KUMAR, K. SATKU, JIE LIU, YAN SHEN \\ From the National University of Singapore, Republic of Singapore
}

We studied the origin of the anterior deltoid from the lateral third of the clavicle and the leading anterior edge of the acromion in 18 cadaver shoulders by anatomical and histological methods.

The main origin of the deltoid was from the superior surface of the anterior acromion, but muscle and tendinous attachments were also seen on the entire anterior surface of the acromion, its anteroinferior surface and on the whole width of the anterior surface of the clavicle.

Mock arthroscopic acromioplasty was shown to detach deltoid fibres from the anterior surfaces, leaving the superior attachment in continuity. Potentially, arthroscopic subacromial and clavicular resection can detach deltoid fibres originating from the anterior and anteroinferior surfaces of the acromion and clavicle and thus weaken the anterior deltoid.

J Bone Joint Surg [Br] 1997;79-B:680-3.

Received 21 October 1996; Accepted after revision 28 January 1997

In 1972, Neer ${ }^{1}$ first described anterior acromioplasty for chronic impingement syndrome of the shoulder, and considered that a beaked acromion with an inferior spur was an important aetiological factor in impingement and subsequent tears of the cuff. In 1993, Rockwood and Lyons ${ }^{2}$ suggested that inferior acromioplasty was insufficient and that additional removal of the anterior extension of the acromion beyond the clavicle gave good results after the failure of the classical Neer acromioplasty. Both Neer ${ }^{1}$ and Rockwood and Lyons ${ }^{2}$ recognised the importance of the anterior fibres of the deltoid, and emphasised the need for

V. P. Kumar, FRCS Ed, FRCS G, FAM, Associate Professor K. Satku, MMed, FRCS Ed, FAM, Associate Professor

J. Liu, MD, Research Assistant

Y. Shen, MD, Research Assistant

Department of Orthopaedic Surgery, National University of Singapore, 5

Lower Kent Ridge Road, Singapore 119260, Republic of Singapore.

Correspondence should be sent to Dr V. P. Kumar

(c)1997 British Editorial Society of Bone and Joint Surgery 0301-620X/97/47353\$2.00 careful reattachment to the acromion at the end of the operation.

Arthroscopic subacromial decompression was shown to be an effective alternative to open operation both for impingement and cuff tears by Ellman, ${ }^{3,4}$ Gartsman $^{5}$ and others. ${ }^{6-8}$ The morbidity was reduced, and earlier rehabilitation was possible, allowing return to work and activities. ${ }^{5,9}$ There were no significant differences in long-term pain relief when compared with open operation which made arthroscopic treatment attractive, at least for the cases of simple impingement without a cuff tear. ${ }^{4,5}$

Arthroscopic anterior inferior acromioplasty necessarily detaches some of the anterior fibres of the deltoid and could leave the shoulder weak in flexion. ${ }^{2}$ It does not allow resection of the acromion to extend anteriorly beyond the clavicle, as recommended by Rockwood and Lyons, ${ }^{2}$ without danger of complete detachment of the important anterior fibres. ${ }^{10}$

Our aim was to use gross anatomical and histological studies to define the relationship of the origin of deltoid muscle fibres to the leading anterior edge of the acromion and the lateral clavicle.

\section{MATERIALS AND METHODS}

We studied 18 fresh shoulders from 11 adult cadavers. Lateral radiographs were taken in a longitudinal axis to show the anterior slope of the acromion.

The skin was dissected from the shoulder girdle through a coronal incision to expose the deltoid origin. The undersurface of the acromion was palpated and inspected for spurs; the rotator cuff was assessed for tears on both the bursal and articular surfaces. These two steps were carried out after disarticulation of the glenohumeral joint.

On two specimens we performed a mock anterior inferior acromioplasty using a burr to remove the anterior inferior edge of the acromion after the removal of all the bursa from the undersurface of the acromion.

Gross anatomy. In six shoulders we made a detailed anatomical dissection of the origin of the deltoid muscle fibres from the anterior acromion and the lateral third of the clavicle.

Histological examination. In 12 shoulders, including the two after mock acromioplasty, specimens were prepared for 


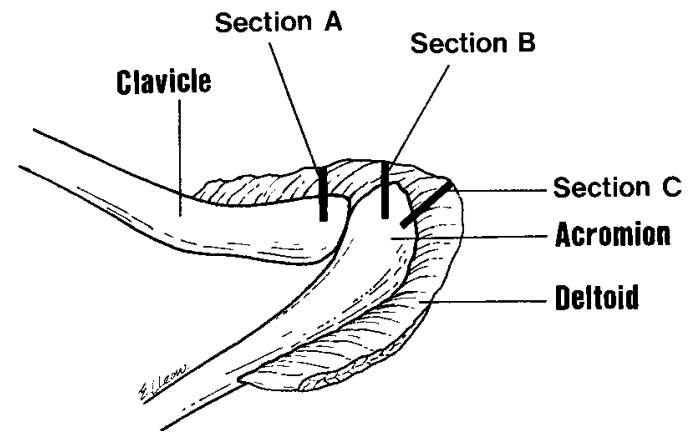

Fig. 1

Diagram of the acromioclavicular junction from above to show the sites of sections taken for histological studies.

histological examination, taking $5 \mathrm{~mm}$ transverse sections through the clavicle-deltoid junction near the acromioclavicular joint, and along the anterior edge of the acromion (Fig. 1). Paraffin sections were prepared and $5 \mu \mathrm{m}$ sections were stained with Masson's trichrome to show the collagen in striated muscle and in the tendinous origin of the deltoid. We measured the thickness of the anterior edge of the acromion in all specimens except those on which the mock surgery had been carried out.

\section{RESULTS}

Radiography and gross anatomy. Three of the 18 acromions were type II according to the classification of Bigliani, Morrison and April ${ }^{11}$ and 15 were type I. The type-II acromions all had a distinct spur on their undersurface, and two of the three were associated with full-thickness tears of the supraspinatus tendon. All the other specimens had intact rotator cuffs.

Of the whole anterior origin of the deltoid from its lateral edge to the most medial origin from the clavicle, $25 \%$ was from the acromion.

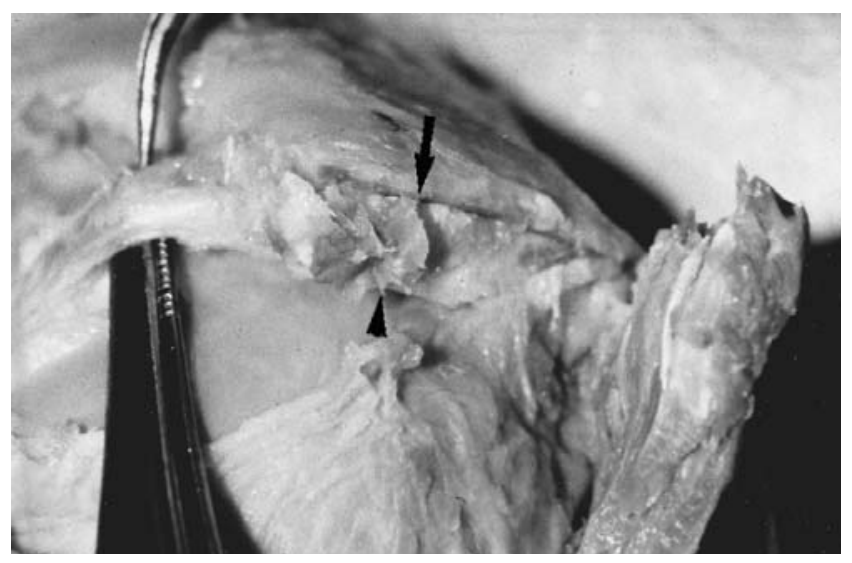

Fig. 2

The deltoid attachment to the anterior acromion showing fibres originating from the upper (arrow) to the lower (arrow head) edges of that surface.
The deltoid arose from the entire anterior surface of the lateral clavicle by a complete muscle attachment to the periosteum. The attachment to the anterior acromion was by a mixture of tendinous and muscle fibres to part of its superior surface and the whole of its anterior surface (Fig. 2). There were strong tendinous fibres over the superior surface of the acromion, with three to four tendinous septae descending into the main multipennate muscle belly of the deltoid. The fibrous insertion of the coracoacromial ligament covered the inferior surface of the acromion (Fig. 3). Histological examination. This confirmed the muscle fibre attachment to the periosteum of the clavicle over its entire anterior surface (Fig. 4).

There was a concentration of collagen and muscle fibres over the superior surface of the acromion (Fig. 5) and on its anterior surface. The dense collagen covering the inferior surface of the acromion, away from the anterior edge, was derived from the coracoacromial ligament (Fig. 5). The deltoid origin from the anterior surface of the acromion was tendinous with interspersed muscle fibres giving a layered appearance.

Specimens which had undergone a mock acromioplasty showed that about $70 \%$ of the origin of the deltoid from the anterior acromion had been detached, leaving only the superior and anterosuperior attachments (Fig. 6). The amount of detachment depended on the extent of bone removal, but there was little retraction of muscle fibres because the tough superior origin remained intact.

The mean thickness of the leading anterior edge of the acromion in 16 specimens was $8.25 \mathrm{~mm} \pm 1.82 \mathrm{~mm}$ (5 to 11).

\section{DISCUSSION}

Both arthroscopic and open operations on the shoulder may damage the origin of the deltoid, making its detailed anatomy important. Standard texts of anatomy ${ }^{12,13}$ are not

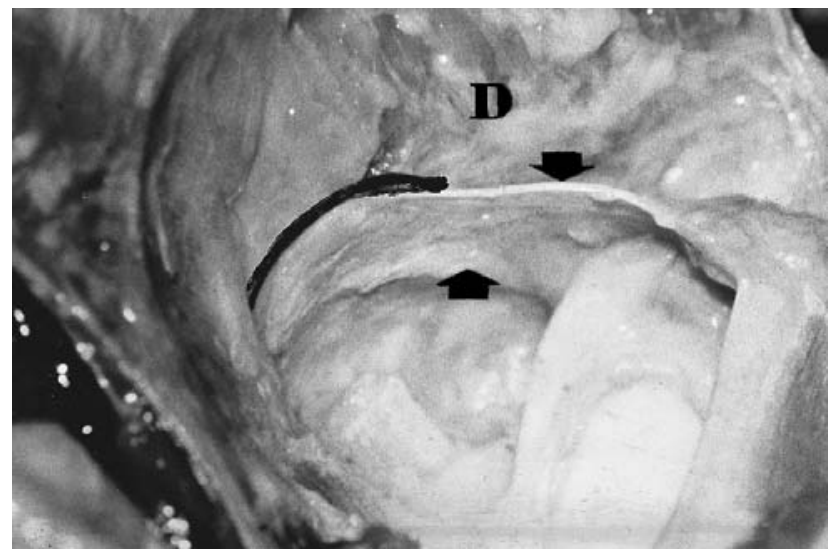

Fig. 3

Specimen of the acromion showing the insertion of the coracoacromial ligament (arrows) on its undersurface. The black line indicates the anterior margin of the acromion from which part of the deltoid (D) takes its origin. 


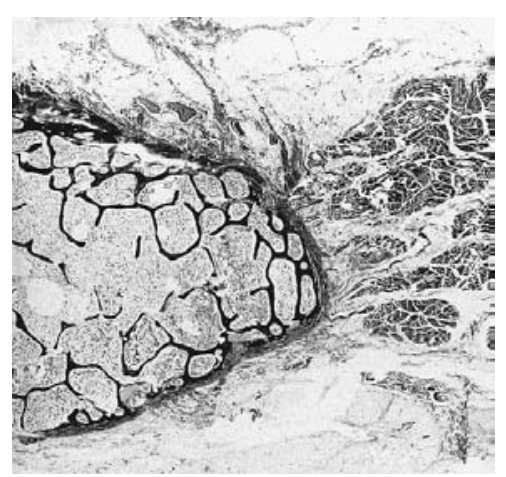

Fig. 4

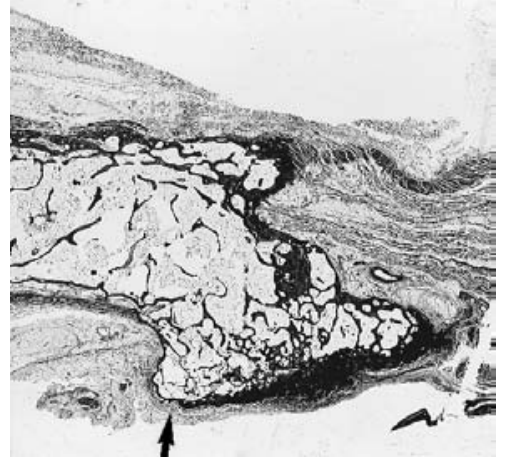

Fig. 5

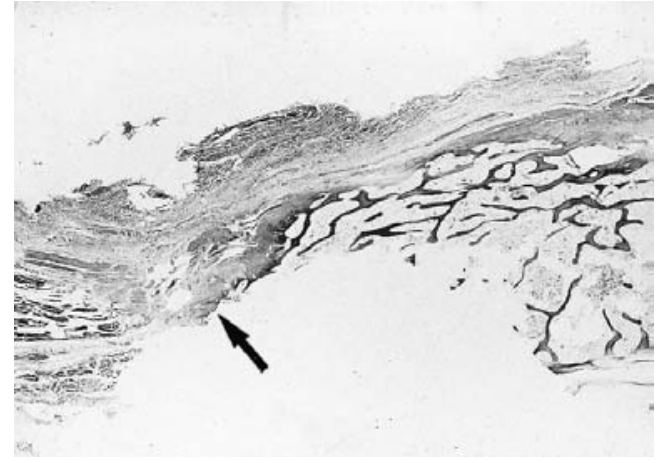

Fig. 6

Figure 4 - Histological section A showing deltoid muscle fibres arising from the entire anterior surface of the clavicle (Masson trichrome $\times 0.75$ ). Figure 5 - Histological section B showing the wide origin of deltoid fibres from the superior to the inferior edge of the acromion. There are muscle and tendinous origins from the superior surface. The insertion of the coracoacromial ligament is seen on the inferior surface, and there is a spur (arrow) (Masson trichrome $\times 0.75)$. Figure 6 - Histological section B after a mock acromioplasty. Some deltoid fibres have been detached from the bone (arrow), but the dense collagenous origin from the superior surface persists. There is minimal retraction of the detached deltoid fibres (Masson trichrome $\times 0.75$ ).

clear and may be deceptive.

William and Warwick ${ }^{12}$ in Gray's anatomy describe the deltoid as originating from the superior surface and anterior border of the lateral third of the clavicle, as do Grant and Smith. ${ }^{14}$ Jenkins ${ }^{13}$ described the origin as from the anterior edge of the lateral third of the clavicle, but the anterior aspect of the clavicle has a surface and not an edge or a border as implied by these authors. We found that the deltoid originated from the entire curved anterior surface of the lateral third of the clavicle, directly from its periosteum (Fig. 4).

William and Warwick ${ }^{12}$ stated that the origin of the deltoid was from the lateral margin and superior surface of the acromion, as did Grant and Smith. ${ }^{14}$ Our work emphasises that the deltoid arises from the superior surface and the whole of the anterior surface of the acromion, with prominent tendinous origins from the superior surface.

The width of the leading edge of the acromion has been poorly appreciated in anatomy texts, ${ }^{12,13}$ but is important in relation to acromioplasty. We found an average thickness of $8.25 \mathrm{~mm}$; Speer, Lohnes and Garrett ${ }^{15}$ removed 6 to $8 \mathrm{~mm}$ from the anterior edge of the acromion at arthroscopic acromioplasty and claimed that there was no deltoid detachment. Sampson et $\mathrm{al}^{9}$ removed $9 \mathrm{~mm}$ of the thickness of the anterior acromion and also reported minimal deltoid detachment. There are probably ethnic differences in the size and thickness of the acromion (ours may have been smaller), but it is highly unlikely that deltoid detachment will be avoided when acromioplasty was performed as described. $^{3,4}$

The importance of the anterior deltoid for shoulder function is well known, ${ }^{1,4}$ but if a Neer acromioplasty ${ }^{1,16}$ is to be performed arthroscopically, detachment of deltoid fibres is inevitable, even if the strong superior origin is preserved. If the anterior portion of the acromion beyond the clavicle is resected, as advocated by Rockwood and Lyons, ${ }^{2}$ arthroscopic acromionectomy must detach the whole acromial origin of the anterior deltoid including those fibres arising from this part of its superior surface. Reconstitution of the deltoid origin is possible at open surgery, but not at an arthroscopic procedure. Since the results of open and arthroscopic procedures are similar, with those of the latter being slightly better, ${ }^{4,5}$ the open procedure is probably unnecessarily excessive, producing considerable deltoid dysfunction. Arthroscopic resection may address the pathology with greater accuracy, since it is performed under direct vision and with greater precision. ${ }^{9}$ When the impinging spur only is removed, without necessarily resecting a significant portion of the acromion, the deltoid origin is not severely violated, since detached fibres may still have links with the overlying periosteum. Our mock acromioplasty, using a burr in cadaver shoulders, also produced some detachment of deltoid fibres from their anterior acromial origin, but there was little retraction of the muscle fibres because of the fibrous interconnections between them and intact fibres and the fact that the superior attachment had been preserved. We also showed that only $25 \%$ of the anterior deltoid arises from the acromion, and that remaining clavicular fibres will help to compensate for partial loss.

Although we showed that some detachment of anterior deltoid fibres occurs at arthroscopic acromioplasty, this is unlikely to compromise function, as borne out by clinical studies. ${ }^{4,5}$ It seems that the superior and anterosuperior origins of the deltoid are more important; these are preserved during an arthroscopic procedure. To confirm this, controlled studies will be needed to determine the strength and endurance of the anterior deltoid after open or arthroscopic acromioplasty.

This work was supported by the grant from the National University of Singapore (RP950380). We thank Mr E. L. Leow for the diagram, Mr B. $\mathrm{K}$. Tan for the photographs and $\mathrm{Ms} \mathrm{M}$. F. Ng for the secretarial assistance.

No benefits in any form have been received or will be received from a commercial party related directly or indirectly to the subject of this article. 


\section{REFERENCES}

1. Neer CS II. Anterior acromioplasty for the chronic impingement syndrome in the shoulder: a preliminary report. J Bone Joint Surg [Am] 1972;54-A:41-50.

2. Rockwood CA Jr, Lyons FR. Shoulder impingement syndrome: diagnosis, radiographic evaluation, and treatment with a modified Neer acromioplasty. J Bone Joint Surg [Am] 1993;75-A:409-24.

3. Ellman H. Arthroscopic subacromial decompression: a preliminary report. Orthop Trans 1985;9:49.

4. Ellman H. Arthroscopic subacromial decompression: analysis of 1-3 year results. Arthroscopy 1987;3:173-81.

5. Gartsman GM. Arthroscopic acromioplasty for lesions of the rotator cuff. J Bone Joint Surg [Am] 1990;72-A:169-80.

6. Burns TP, Turba JE. Arthroscopic treatment of shoulder impingement in athletes. Am J Sports Med 1992;20:13-6.

7. Adolfsson L, Lysholm J. Results of arthroscopic acromioplasty related to rotator cuff lesions. Int Orthop 1993;17:228-31.

8. Beach WR, Caspari RB. Arthroscopic management of rotator cuff disease. Orthopedics 1993;16:1007-15.
9. Sampson TG, Nisbet JK, Glick JM. Precision acromioplasty in arthroscopic subacromial decompression of the shoulder. Arthroscopy 1991;7:301-7.

10. Groh GI, Simoni M, Rolla P, Rockwood CA. Loss of the deltoid after shoulder operations: an operative disaster. J Shoulder Elbow Surg 1994;3:243-53.

11. Bigliani LH, Morrison DS, April EW. The morphology of the acromion and its relationship to rotator cuff tears. Orthop Trans 1986; 10:228.

12. William PL, Warwick R. Myology. In: William PL, Warwick R, eds. Gray's anatomy. 36th ed. Edinburgh: Churchill Livingstone, 1980: 506-619.

13. Jenkins DB. The upper limb. In: Jenkins DB, ed. Hollinshead's functional anatomy of the limbs and back. 6th ed. Philadelphia: WB Saunders Company, 1991:84-5.

14. Grant JCB, Smith CG. The musculature. In: Schaeffer JP, ed. Morris' human anatomy: a complete systemic treatise. 11th ed. New York: McGraw Hlll Book Company, 1953:399-609.

15. Speer KP, Lohnes J, Garrett WE Jr. Arthroscopic subacromial decompression: results in advanced impingement syndrome. Arthroscopy 1991;7:291-6.

16. Neer CS II. Impingement lesions. Clin Orthop 1983;173:70-7. 